УДК 622.24.053-752.2

МОДЕРНИЗАЦИЯ ДЕМПФИРУЮЩЕГО УСТРОЙСТВА И АНАЛИЗ РАБОТОСПОСОБНОСТИ КОМПОНОВКИ НИЗА БУРИЛЬНОЙ кОЛОННЫ

\title{
DAMPING DEVICE MODERNIZATION AND ANALYSIS OF THE DOWNHOLE DRILL STRING ASSEMBLY CAPABILITY
}

А.С. Гаркин, Г.Р. Игтисамова, Э.Я. Зинатуллина, С.В. Назаров

Уфимский государственный нефтяной технический университет, г. Уфа, Российская Федерация

Anton S. Garkin, Galia R. Igtisamova, Elmira Ya. Zinatullina, Sergey V. Nazarov

Ufa State Petroleum Technological University, Ufa, Russian Federation e-mail: ACGarkin@mail.ru

Аннотация. В данной статье рассмотрены виды вибраций, которые возникают в компоновке низа бурильной колонны (КНБК) при бурении скважин, а также причины, последствия и способы их гашения. Было выявлено, что рассматриваемые методы для снижения таких вибраций, как осевая, крутильная и радиальная, не всегда позволяют достичь нужных результатов. В этом случае наиболее эффективным способом их устранения являются демпфирующие устройства.

Предложена модернизированная конструкция демпфера гидромеханического (ДГМ-240), в которой гашение вибраций происходит пакетом тарельчатых пружин, а шток выполнен с винтообразным пазом, который позволяет гасить торсионные вибрации.

Разработана математическая модель, описывающая работу КНБК, представленная системой дифференциальных уравнений второго порядка, 
решение которой было выполнено с использованием программного пакета MathCAD 2015. Построены и проанализированы графики возникновения вибраций в КНБК без и с модернизированным демпфером.

Abstract. This article discusses the types of vibrations that occur in the downhole drill string assembly (DDSA) during drilling, as well as the causes, consequences and methods of their damping. It was found that the considered methods for reducing such vibrations as axial, torsional and radial methods do not always allow to achieve the desired results. In this case, the most effective way to eliminate them is damping devices. A modernized design of a hydromechanical damper is proposed.

A modernized design of a hydromechanical damper (DGM-240) is proposed, in which the vibration damping occurs with a package of disk springs, and the rod is made with a helical groove that allows damping torsional vibrations.

A mathematical model was developed describing the DDSA work, represented by a system of second-order differential equations, which was solved using the MathCAD 2015 software package. The graphs of vibrations in the DDSA without and with a modernized damper were built and analyzed.

Ключевые слова: вибрация, демпфирующее устройство, скважинное оборудование, бурильная колонна, долото, бурение скважин

Key words: vibration, damping device, down hole equipment, drill string, bit, drilling

Бурение нефтяных и газовых скважин - сложный многофакторный процесс. Рациональная эксплуатация имеющегося в наличии парка буровой техники, в том числе и глубинного оборудования, становится все более актуальной задачей бурения [1]. 
Использование забойного инструмента при бурении скважин связано с различными динамическими процессами. Одним из основных источников отказов элементов компоновки низа бурильной колоны являются: осевые (рисунок $1, a)$, крутильные (рисунок 1, б) и продольные (рисунок 1,8 ) вибрации $[2,3]$.

Главными факторами возникновения вибраций бурильного инструмента являются утрата контакта между долотом и забоем, пульсация давления в системе нагнетания буровой установки (БУ), разрушение горных пород прерывистым действием, контактная поверхность породоразрушающего инструмента с зубчатым профилем.

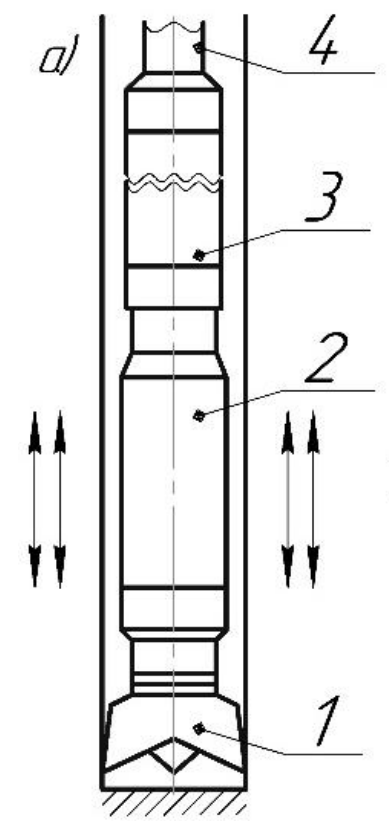

a)

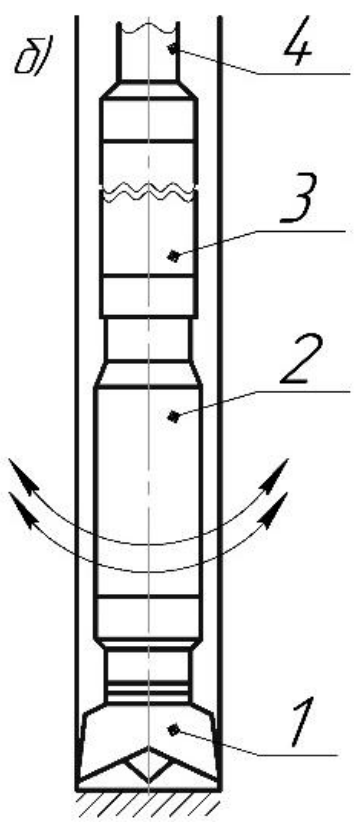

б)

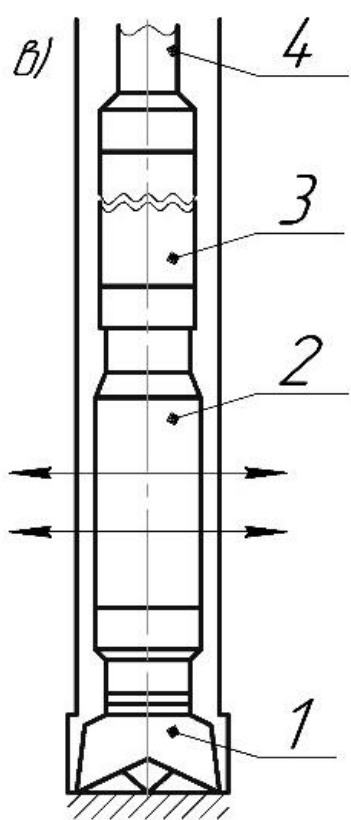

B)

1 - долото; 2 - забойный двигатель;

3 - утяжеленные бурильные трубы (УБТ);

4 - бурильные трубы

а) осевая вибрация; б) крутильная вибрация; в) продольная вибрация

Рисунок 1. Виды вибраций компоновки бурильной колонны

Продольные вибрации бурильной колонны, возбуждаемые шарошечным долотом, а также создаваемые ими динамические силы увеличивают интенсивность разрушения породы, но одновременно с этим уменьшают долговечность бурильной колонны. 
В процессе бурения турбинным методом, в том числе турбобурами, технологический процесс осложняется тем, что забойные гидравлические двигатели в определенных условиях служат причиной усиленных вибраций. Кроме того, в системе при наличии нелинейных сил сопротивления, которые зависят от скорости движения, могут появляться крутильные и продольные автоколебания.

Вибрации в прочессе бурения турбинным методом:

- ускоряют износ и разрушение шарошечных долот и забойных двигателей;

- вызывают возникновение больших усталостных напряжений в колонне бурильных труб, в особенности в ее резьбовых соединениях;

- уменьшают величину момента, передаваемого колонной бурильных труб при роторном бурении;

- способствуют образованию в стволе скважины каверн и желобных выработок, которые могут быть причиной различных осложнений.

Кроме того, необходимо отметить, что все виды вибраций между собой взаимосвязаны. Комбинированные вибрации появляются тогда, когда первичные достигают максимальных значений. Например, крутильные вибрации могут приводить к продольным и/или осевым вибрациям; продольные вибрации могут порождать осевые вибрации; осевые вибрации приводить к продольным вибрациям. Подобное проявление вибрации затрудняет представление происходящего на забое скважины.

С целью защиты от вибрации осуществляют покрытие бурильной колонны антивибрационной смазкой, внедрение легкосплавных бурильных труб (ЛБТ), а также включение в состав бурильной колонны стабилизирующих устройств, маховиков и калибраторов, которые способствуют улучшению показателей бурения, но существенное уменьшение этих отрицательных явлений достигается путем применения демпфирующих устройств. 
Снижение прочности и долговечности бурильной колонны вызывается как высокочастотными, так и низкочастотными вибрациями [4]. В связи с этим принцип работы и конструкция демпфирующего устройства должны обеспечивать максимальное гашение и отражение как высокочастотных, так и низкочастотных вибраций бурильной колонны и соответствующее уменьшение динамических сил в бурильных трубах, вызываемых этими вибрациями.

В работах А.В. Лягова [5-7] отмечено, что наиболее работоспособной конструкцией является виброгаситель гидромеханического типа.

Рассмотрев конструкцию гидромеханического демпфирующего устройства ДГМ-240 (рисунок 2), были выявлены следующие недостатки:

- при больших нагрузках происходит соударение соседних витков винтовой пружины, что, в свою очередь, приводит к ее износу;

- данная конструкция способна гасить только осевые вибрации.

С целью повышения надежности, расширения области применения, способности регулирования параметров оборудования предлагается модернизация ДГМ-240 (рисунок 3), а именно следующее:

- винтовая пружина заменена на пружину тарельчатого типа;

- шлицевое соединение корпуса и штока заменено на сферическое соединение через набор шариков;

- канавки под шары выполнены в спиральной плоскости.

Модернизированный демпфер состоит из корпуса, в цилиндрической полости которого установлена направляющая грязезащитная втулка с тарельчатой пружиной. На сопрягаемой с поверхностью цилиндрической полости корпуса поверхности поршня размещены уплотнительные манжеты и кольца. Поршень свинчивается по резьбе М155х6 со штоком. 


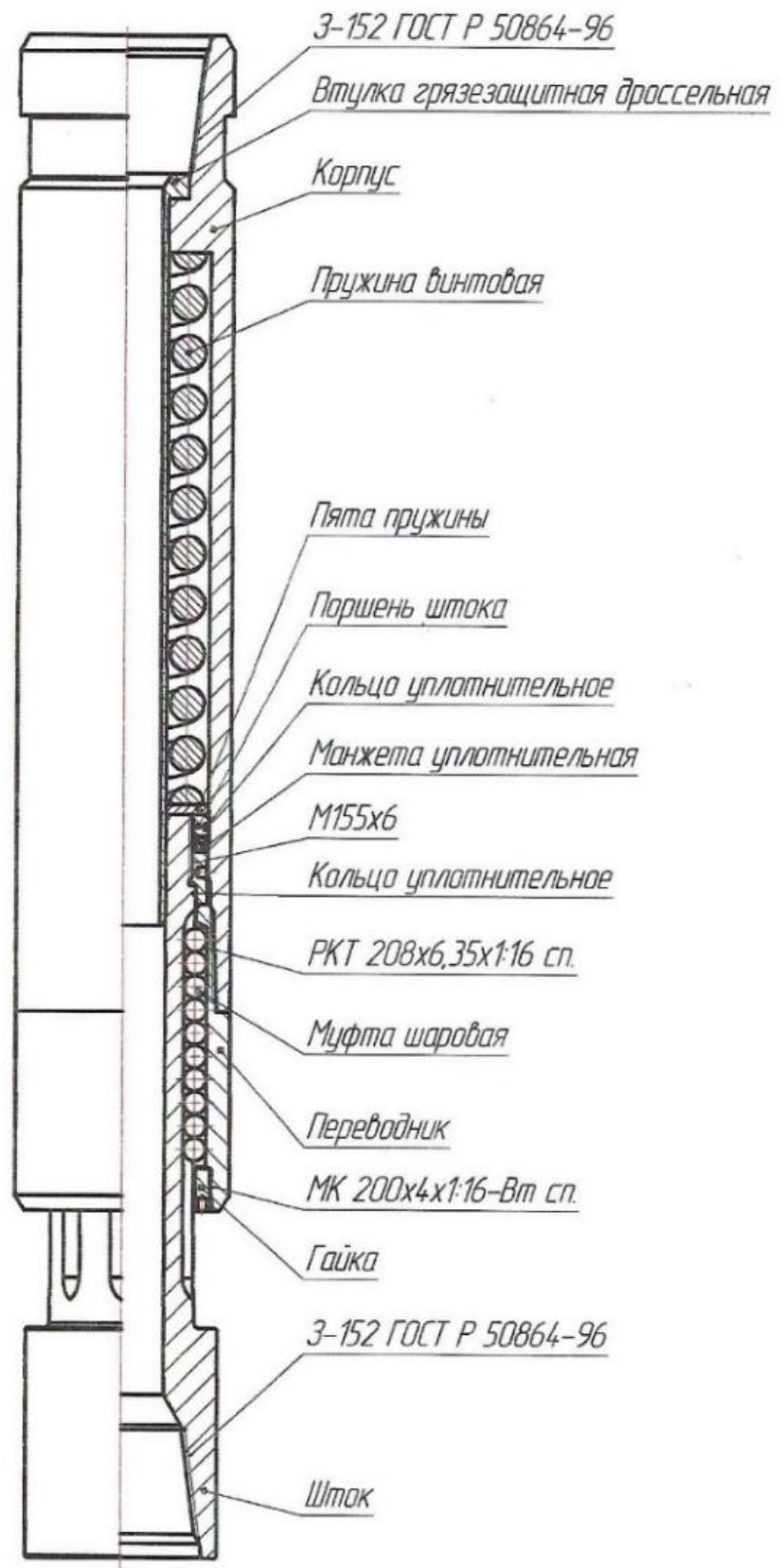

Рисунок 2. Конструкция гидромеханического демпфирующего устройства ДГМ-240

Их соединение герметизировано уплотнительным кольцом, установленным на буртике штока. В штоке и переводнике восемь спиральных канавок, в которых размещены 80 шаров диаметром 25 мм, ограниченных гайкой, ввернутой по резьбе М220x4 снизу в переводник. В центральном канале штока может быть установлена гидромониторная насадка. В верхней части корпуса и нижней части штока выполнены муфтовые присоединительные к колонне бурильных труб замковые резьбы 3-152. 


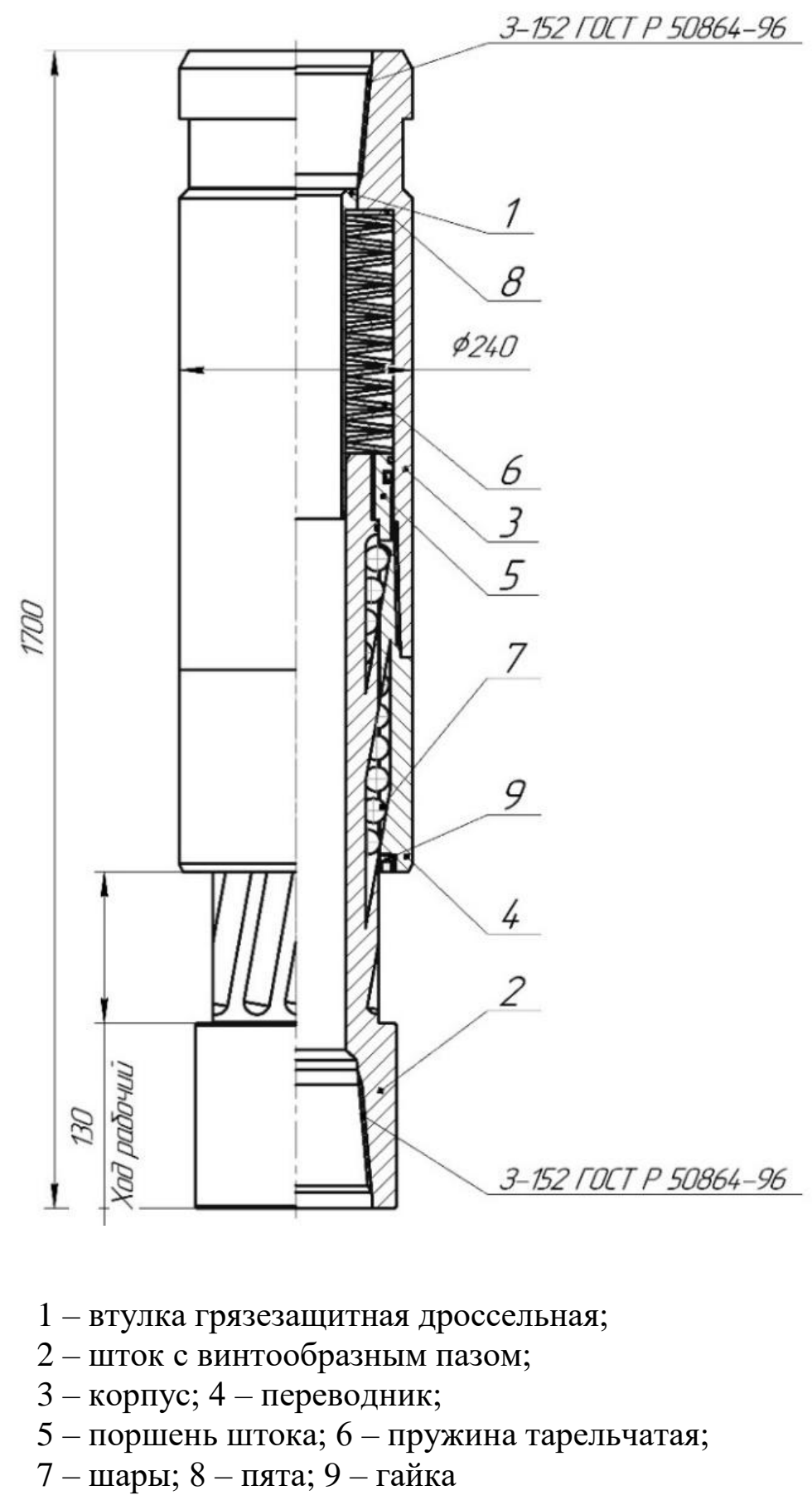

Рисунок 3. Модернизированная конструкция гидромеханического демпфирующего устройства ДГМ-240

Рассмотрены продольные вибрации бурильного инструмента в составе следующей компоновки нижней части бурильной колонны. КНБК включает долото 269,9 Т-ЦВ, турбобур 3ТСШ1-240, бурильные трубы Ø 140 мм, модернизированное демпфирующее устройство ДГМ-240.

Представим феноменологическую модель колебательной системы динамически возмущенной нижней части бурильной колонны (рисунок 4). 




$m_{1}$ - масса долота с забойным двигателем;

$m_{2}$ и $k_{2}$ - масса и коэффициент упругости бурильных труб (БТ)

с демпфирующим устройством;

$k_{1}$ и $c$ - упругости и вязкости осевой опоры шпиндельной секции;

$X_{1}(t), X_{2}, X_{3}$-координаты движения

\section{Рисунок 4. Феноменологическая модель КНБК}

Долото с забойным двигателем массой $m_{1}$ совершает перемещение по ухабообразному забою, профиль которого зависит от координаты $X_{1}(t)$.

Для описания функции перемещения корпуса долота при бурении твердых пород используем выражение [5]:

$$
X_{1}(t)=A \cdot[1+2 \cdot \cos (\varepsilon \cdot t)] \cdot \sin (\omega \cdot t),
$$

где $A$ - амплитуда, мм;

$\varepsilon-$ круговая частота, $\mathrm{c}^{-1}$;

$t$ - время, с;

$\omega$ - несущая частота, $\mathrm{c}^{-1}$.

Построим силовые схемы, показывающие характер нагружения масс (рисунок 5). 
a) $\quad \Sigma c\left(\dot{X}_{2}-\dot{X}_{3}\right)$

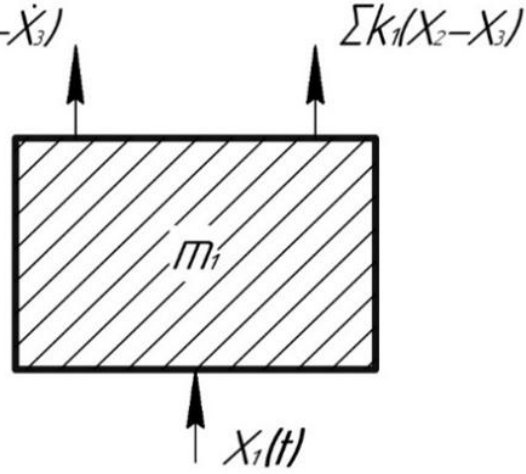

a)

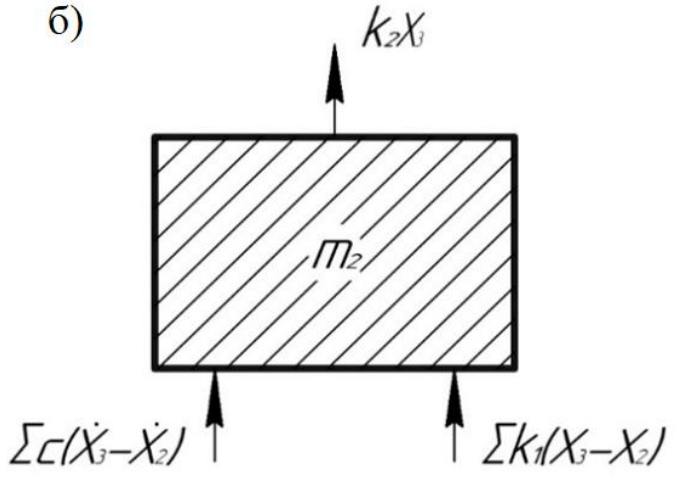

б)

a) силовая схема нагружения долота с забойным двигателем;

б) силовая схема нагружения бурильных труб с демпфирующим устройством

Рисунок 5. Силовые схемы феноменологической модели КНБК

Суммируя динамические силы относительно соответствующих масс, запишем уравнения движения рассматриваемой компоновки:

$$
\left\{\begin{array}{l}
m_{1} \cdot \ddot{X}_{2}=-X_{1}(t)-c \cdot\left(\dot{X}_{2}-\dot{X}_{3}\right)-k_{1} \cdot\left(X_{2}-X_{3}\right) ; \\
m_{2} \cdot \ddot{X}_{3}=-c \cdot\left(\dot{X}_{3}-\dot{X}_{2}\right)-k_{1} \cdot\left(X_{3}-X_{2}\right)-k \cdot X_{3} \\
X_{1}(t)=A \cdot[1+2 \cdot \cos (\varepsilon \cdot t)] \cdot \sin (\omega \cdot t),
\end{array}\right.
$$

где $X_{i}$ - пространственные координаты, характеризующие динамические отклонения соответствующих точек системы от положения статического равновесия рассматриваемой модели;

$\dot{X}_{i}$ и $\ddot{X}_{i}-$ скорости и ускорения соответствующих точек системы;

$X_{1}(t)$ - перемещения корпуса долота при бурении твердых пород;

$X_{2}$ - реализация перемещения забойного двигателя;

$X_{3}$ - поведение (перемещение) динамически возмущенной колонны с демпфирующим устройством.

Демпфирующее устройство устанавливается в месте, определенном расчетом, где продольные вибрации распространяются с большой скоростью. Длина динамически возмущенного участка (место установки виброгасителя) рассчитывается по формуле [8]: 


$$
L=\frac{30 \cdot a}{n_{\mathrm{T}} \cdot K_{\mathrm{W}} \cdot K_{\mathrm{B}}},
$$

где $a$ - скорость распространения продольных волн в бурильной колонне;

$n_{\text {т }}$ - частота вращения вала двигателя, мин ${ }^{-1}$;

$K_{\text {ш }}$ - число шарошек долота;

$K_{\mathrm{B}}-$ эмпирический коэффициент.

При перекатывании шарошек по забою скважины появляются несколько гармоник зубцовых вибраций с частотами, отличающимися между собой на малую величину $\varepsilon$. Так как высота зубцов периферийных венцов шарошек практически постоянна, то с известной точностью можно принять, что амплитуды всех трех гармоник равны некоторой величине $A$.

Уравнения движения компоновки (2) являются системой нелинейных однородных дифференциальных уравнений второго порядка. Введём обозначения: $Y_{0} \equiv X_{2}, Y_{1} \equiv \dot{Y}_{0}, Y_{2} \equiv X_{3}, Y_{3} \equiv \dot{Y}_{2}$.

После очевидных преобразований система примет вид:

$$
\left\{\begin{array}{l}
\dot{Y}_{0}=Y_{1} \\
\dot{Y}_{1}=-m_{1}^{-1} \cdot\left[X_{1}(t)+c \cdot\left(Y_{1}-Y_{3}\right)+k_{1} \cdot\left(Y_{0}-Y_{2}\right)\right] \\
\dot{Y}_{2}=Y_{3} \\
\dot{Y}_{3}=-m_{2}^{-1} \cdot\left[c \cdot\left(Y_{3}-Y_{1}\right)+k_{1} \cdot\left(Y_{2}-Y_{0}\right)+k_{2} \cdot Y_{2}\right] .
\end{array}\right.
$$

Решение данной системы осуществлялось в рамках пакета MathCAD 2015.

На рисунке 6 показан график возникновения осевых вибраций КНБК без демпфирующего устройства, на котором видно, что при бурении твердой породы амплитуда вибраций достигает 1,2 мм. За счет внедрения модернизированного оборудования на графике (рисунок 7) прослеживается тенденция к гашению вибраций (изменение амплитуды до 0,03 мм). Применение усовершенствованного демпфера позволило снизить амплитуду вибраций в 40 раз. 


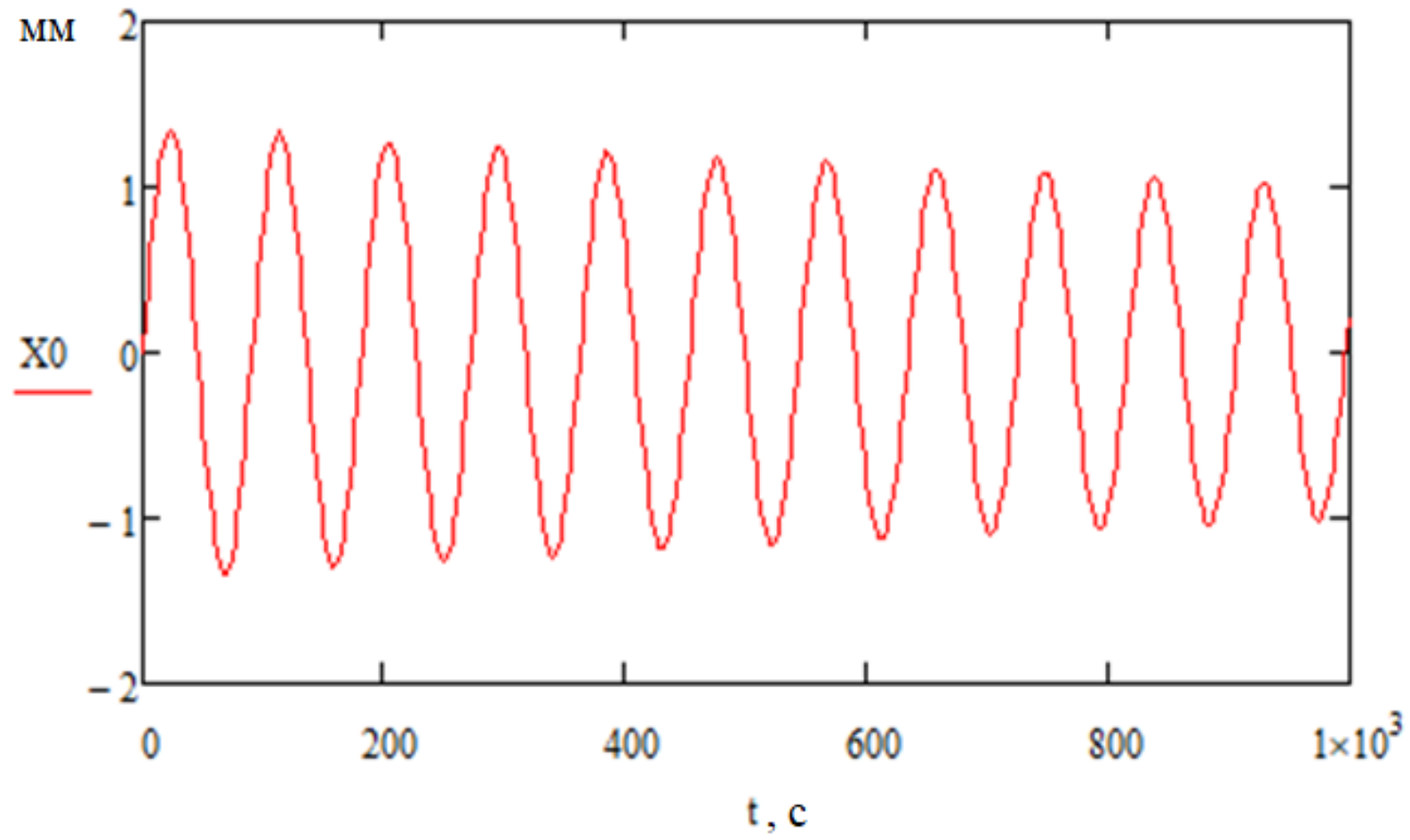

Рисунок 6. График возникновения осевых вибраций КНБК без демпфера

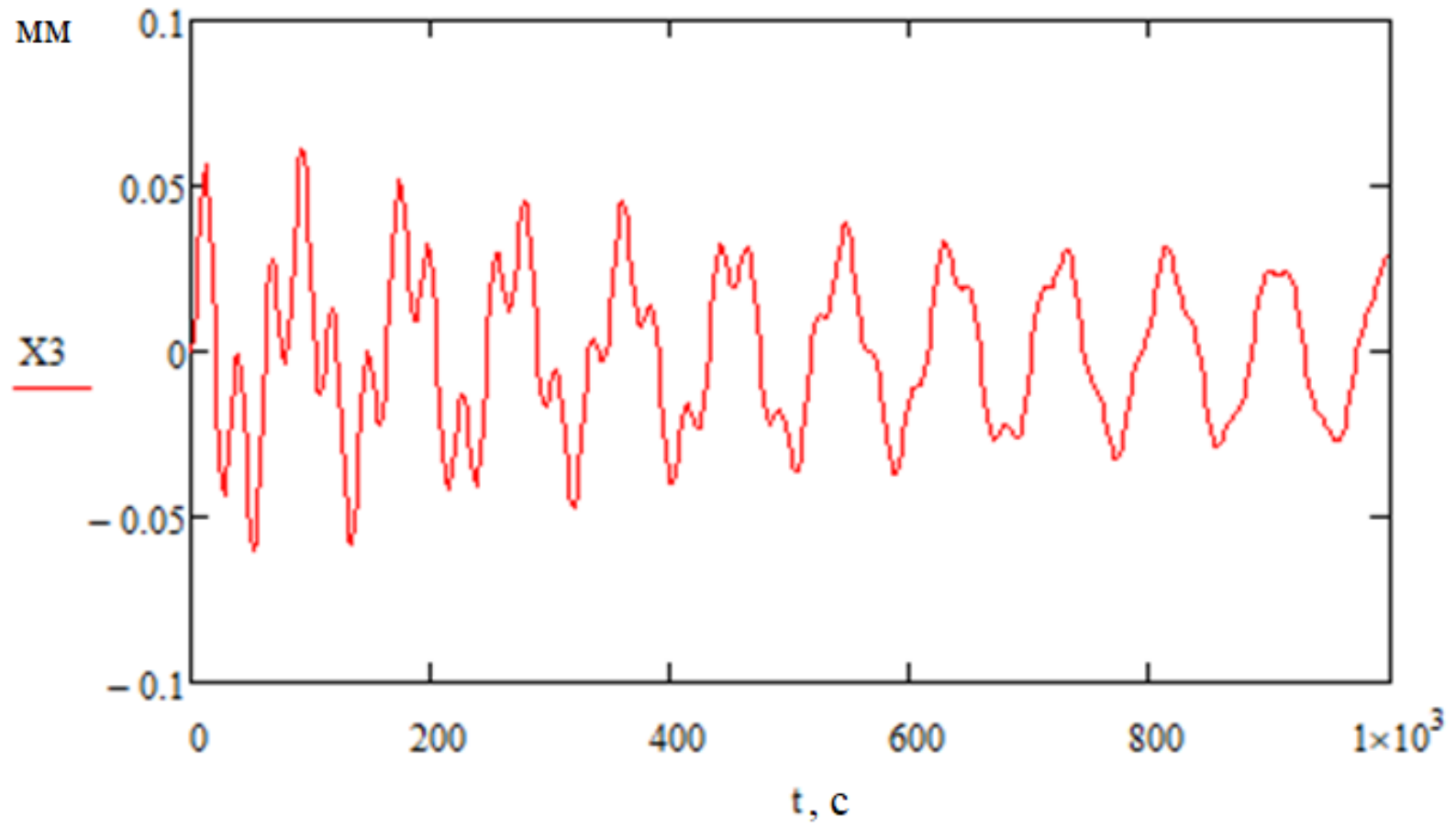

Рисунок 7. График поведения (перемещения) динамически возмущенной колонны с демпфирующим устройством 


\section{Выводы}

1. Предложена модернизированная конструкция гидромеханического демпфирующего устройства ДГМ-240, в котором:

- гашение вибраций происходит пакетом тарельчатых пружин, обеспечивающие оптимальную жёсткость оборудования и позволяющие выдерживать высокие осевые нагрузки, передающиеся на виброгаситель;

- шток выполнен с винтообразным пазом гасящий торсионные вибрации.

2. Разработана математическая модель, описывающая работу КНБК с модернизированным демпфирующим устройством ДГМ-240, представленная системой дифференциальных уравнений второго порядка, решение которой выполнено с использованием программного пакета MathCAD 2015. За счет внедрения виброгасителя в компоновку низа бурильной колоны наблюдается тенденция к гашению вибраций (изменение амплитуды от 1,2 до 0,03 мм).

\section{Список используемых источников}

1. Заляев М.Ф. Исследование вибрации при бурении скважин на Термокарстовом газоконденсатном месторождении // Нефтегазовое дело. 2015. № 4. C. 36-40.

2. Бадретдинов Т.В., Ямалиев В.У. Анализ колебаний бурильной колонны и применения демпфирующих устройств // Нефтегазовое дело. 2016. № 6. C. 5-22.

3. Заляев М.Ф., Ямалиев В.У., Абуталипова Е.М., Авренюк А.Н. О необходимости учета вибрации при конструировании элементов бурильной колонны // Химическое и нефтегазовое машиностроение. 2016. № 9. C. 45-48. 
4. Зинатуллина Э.Я. Разработка управляемых в процессе бурения скважин колтюбинговых компоновок низа бурильной колонны: автореф. дис. ... канд. техн. наук. Уфа, 2009. 24 с.

5. Лягов А.В. Динамические компоновки для бурения забойными двигателями: дис. ... д-ра техн. наук. Уфа, 2005. 480 с.

6. Лягов А.В. Разработка гидродинамических виброгасителей с центраторами для совершенствования технологии турбинного бурения наклонных скважин: дис. ... канд. техн. наук. Уфа, 1985. 262 с.

7. Лягов А.В. Определение коэффициента передачи наддолотных гидромеханических виброгасителей // Современные проблемы буровой и нефтепромысловой механики: межвуз. науч.-темат. сб. Уфа: УГНТУ. 1989. C. 9-13.

8. Балицкий П.В. Взаимодействие бурильной колонны с забоем скважины. М.: Недра, 1975. 293 с.

\section{References}

1. Zalyaev M.F. Issledovanie vibratsii pri burenii skvazhin na Termokarstovom gazokondensatnom mestorozhdenii [The Exploration of Vibration While Drilling Wells on Termokarstovoe Gas Deposit]. Neftegazovoe delo - Petroleum Engineering, 2015, No. 4, pp. 36-40. [in Russian].

2. Badretdinov T.V., Yamaliev V.U. Analiz kolebanii buril'noi kolonny i primeneniya dempfiruyushchikh ustroistv [Analysis of Drill String Vibration and Utilization Damping Device]. Neftegazovoe delo - Petroleum Engineering, 2016, No. 6, pp. 5-22. [in Russian].

3. Zalyaev M.F., Yamaliev V.U., Abutalipova E.M., Avrenyuk A.N. O neobkhodimosti ucheta vibratsii pri konstruirovanii elementov buril'noi kolonny [On the Need to Consider Vibration in the Design of Drill Stem Elements]. Khimicheskoe $i$ neftegazovoe mashinostroenie - Chemical and Petroleum Engineering, 2016, No. 9, pp. 45-48. [in Russian]. 
4. Zinatullina E.Ya. Razrabotka upravlyaemykh $v$ protsesse bureniya skvazhin koltyubingovykh komponovok niza buril'noi kolonny: avtoref. dis. kand. tekhn. nauk [Development of Coiled Tubing Arrangements of the Bottom of the Drill String Controlled in the Process of Drilling: Cand. Engin. Sci. Avtoref.]. Ufa, 2009. 24 p. [in Russian].

5. Lyagov A.V. Dinamicheskie komponovki dlya bureniya zaboinymi dvigatelyami: dis. dok. tekhn. nauk. [Dynamic Layouts for Downhole Drilling: Doc. Engin. Sci. Diss.]. Ufa, 2005. 480 p. [in Russian].

6. Lyagov A.V. Razrabotka gidrodinamicheskikh vibrogasitelei s tsentratorami dlya sovershenstvovaniya tekhnologii turbinnogo bureniya naklonnykh skvazhin: dis. kand. tekhn. nauk. [Development of Hydrodynamic Vibration Dampers with Centralizers to Improve the Technology of Turbine Drilling of Inclined Wells: Cand. Engin. Sci. Diss.]. Ufa, 1985. 262 p. [in Russian].

7. Lyagov A.V. Opredelenie koeffitsienta peredachi naddolotnykh gidromekhanicheskikh vibrogasitelei [Determination of the Transmission Coefficient of the Above-Ground Hydro-Mechanical Vibration Dampers]. Mezhvuzovskii nauchno-tematicheskii sbornik «Sovremennye problemy burovoi i neftepromyslovoi mekhaniki» [Interuniversity Scientific-Thematic Collection «Modern Problems of Drilling and Oilfield Mechanics»]. Ufa, 1989. pp. 9-13. [in Russian].

8. Balitskii P.V. Vzaimodeistvie buril'noi kolonny s zaboem skvazhiny [The Interaction of the Drill String with the Bottom Hole]. Moscow, Nedra Publ., 1975. 293 p. [in Russian]. 


\section{Сведения об авторах}

\section{About the authors}

Гаркин Антон Сергеевич, магистрант кафедры «Машины и оборудование нефтегазовых промыслов», УГНТУ, г. Уфа, Российская Федерация

Anton S. Garkin, Undergraduate Student of Machines and Equipment of Oil and Gas Fields Department, USPTU, Ufa, Russian Federation

e-mail: ACGarkin@mail.ru

Игтисамова Галия Рашитовна, д-р пед. наук, профессор кафедры информационных технологий, математики и естественных наук, УГНТУ, филиал в г. Октябрьском, г. Октябрьский, Российская Федерация

Galia R. Igtisamova, Doctor of Pedagogic Sciences, Professor of Information Technology, Mathematics and Natural Sciences Department, USPTU, Branch, Oktyabrsky, Russian Federation

e-mail: igtisamova_galiy@mail.ru

Зинатуллина Эльмира Якуповна, канд. техн. наук, доцент кафедры «Машины и оборудование нефтегазовых промыслов», УГНТУ, г. Уфа, Российская Федерация

Elmira Ya. Zinatullina, Candidate of Engineering Sciences, Assistant Professor of Oil and Gas Fields Department, USPTU, Ufa, Russian Federation

Назаров Сергей Викторович, канд. техн. наук, доцент кафедры «Машины и оборудование нефтегазовых промыслов», УГНТУ, г. Уфа, Российская Федерация

Sergey V. Nazarov, Candidate of Engineering Sciences, Assistant Professor of Oil and Gas Fields Department, USPTU, Ufa, Russian Federation 